\title{
Crossed cerebellar diaschisis accompanied by hemiataxia: a PET study
}

\author{
Makoto Tanaka, Susumu Kondo, Shunsaku Hirai, Koji Ishiguro, Tomio Ishihara, \\ Mitsunori Morimatsu
}

\begin{abstract}
To study crossed cerebellar diaschisis (CCD), cerebellar blood flow and oxygen metabolism were measured with positron emission tomography (PET) in 12 patients who showed a minimal degree of hemiparesis due to single unilateral supratentorial lesion. Six patients presenting with mild to moderate cerebellar type hemiataxia showed CCD, that is, decreased blood flow and oxygen metabolism in the cerebellar hemisphere contralateral to the side of supratentorial lesion. Hemiataxia and reduced cerebellar blood flow and metabolism occurred in the ipsilateral side. Lesions were located in the thalamus in four patients and the parietal lobe and internal capsule in one each. The other six patients did not exhibit ataxia, and oxygen metabolism was not reduced in the contralateral cerebellar hemisphere. In two of these cases, however, reduced cerebellar perfusion was observed in the contralateral cerebellar hemisphere. These findings indicate that CCD occurs with hemiataxia and suggest that it results not only from disruption of the corticopontocerebellar pathway but also of the dentatorubrothalamic pathway. CCD associated with hemiataxia, demonstrated in patients with thalamic lesions, was presumed to result from retrograde deactivation of the cerebellar hemisphere via the dentatorubrothalamic pathway.
\end{abstract}

Gunma University School of Medicine, Maebashi, Japan

Department of Neurology

Makoto Tanaka

Susumu Kondo

Shunsaku Hirai

Koji Ishiguro

Department of

Radiology

Tomio Ishihara

Department of

Neurology, Ymaguchi

University School of

Medicine, Japan

Mitsunori Morimatsu

Correspondence to: $\mathrm{Dr}$

Tanaka, Department of

Neurology, Gunma

Neurology, Gunma

Medicine, Showa-machi,

Maebashi 371, Japan.

Received 20 August 1990

and in final revised form

14 May 1991.

Accepted 21 May 1991 the clinical presentation of ataxia, a major manifestation of cerebellar dysfunction. An alternative interpretation is that the motor weakness and hypertonicity usually occurring with CCD mask additional motor deficits, including ataxia.

Thalamic injury, especially to the ventrolateral portion, is a well known cause of contralateral hemiataxia. ${ }^{7}$ Although this is explained as being due to destruction of major projections from the cerebellum via the dentato(rubro)thalamic pathway ${ }^{8}$ at the terminal, cerebellar efferent pathways have not been investigated with reference to CCD. We therefore initiated the present study in patients without hemiparesis, which can mask ataxia, and with single lesions in various supratentorial regions.

\section{Materials and methods}

Twelve patients with cerebral infarction or haemorrhage presenting minimal hemiparesis were studied by PET (table 1). They were selected from a consecutive series of patients studied since March 1986 at the Gunma University Hospital Cyclotron Center for PET Diagnosis. All were examined neurologically to ensure the absence of motor impairment due to muscle weakness or hypertonicity, which can mask ataxia. Clinical diagnosis and lesion site were also confirmed by neuroradiological evaluation including brain CT in all patients, angiography in five (cases $1,8,9,11,12$ ) and magnetic resonance imaging (MRI) in six (cases $1,2,7,8,9,12$ ), and by clinical course and neurological findings. All but one patient (case 3) had a single supratentorial lesion without clinical or radiological evidence of cerebellar or brain stem involvement. Of these, six (cases 1 to 6 ) showed mild to moderate cerebellar ataxia with preserved deep sensation (vibration, proprioception, and kinesthesia), while the remaining patients (cases 7 to 12) had no ataxia. A clinical history of cases 1 and 5 has been reported in detail previously. ${ }^{9}$ Four hemiataxic patients had a history of old thalamic haemorrhage or infarction, and one patient (case 1) had infarction in the parietal lobe. Case 3 showed pure motor hemiplegia on examination at the time of onset, which had improved to mild hemiataxia 48 hours later. Although a small capsular or pontine lacune not revealed by $x$ ray CT was suspected as the cause of these transient symptoms, ${ }^{10}$ hypoperfusin and oxygen hypometabolism on the left cerebral hemisphere later revealed by PET favoured a capsular lacune. Thirteen healthy 
Table 1 Details of patients with cerebral infarction or haemorrhage presenting minimal hemiparesis

\begin{tabular}{|c|c|c|c|c|c|c|}
\hline $\begin{array}{l}\text { Case } \\
\text { number }\end{array}$ & $\begin{array}{l}\text { Age } \\
\text { (years) }\end{array}$ & Sex & Neuroimaging findings & Presenting signs and symptoms & Neurological findings on PET study & $\begin{array}{l}\text { Time from onset } \\
\text { to PET study }\end{array}$ \\
\hline 1 & 34 & $\mathbf{F}$ & $\begin{array}{l}\text { Infarction in left parietal cortex and subcortical } \\
\text { white matter }\end{array}$ & $\begin{array}{l}\text { Dysesthesia and clumsiness of } \\
\text { right hand }\end{array}$ & $\begin{array}{l}\text { Right sided hemiataxia, mildly } \\
\text { disturbed combined sensations }\end{array}$ & 13 Months \\
\hline 2 & 56 & $\mathbf{M}$ & $\begin{array}{l}\text { Old haemorrhage localised in left thalamus } \\
\text { (ventrolateral nucleus) }\end{array}$ & Sensorimotor disturbance & $\begin{array}{l}\text { Right sided hemiataxia, dys- and } \\
\text { hyperesthesia }\end{array}$ & 18 Months \\
\hline 3 & 71 & $\mathbf{M}$ & No abnormal findings on repeated CT & $\begin{array}{l}\text { Pure motor hemiplegia in right } \\
\text { side }\end{array}$ & $\begin{array}{l}\text { Right sided hemiataxia without } \\
\text { motor weakness }\end{array}$ & 24 Hours \\
\hline 4 & 47 & $\mathbf{F}$ & $\begin{array}{l}\text { Small localised haemorrhage in right lateral } \\
\text { thalamus at onset, no abnormalities on follow } \\
\text { up CT }\end{array}$ & Sensorimotor disturbances & $\begin{array}{l}\text { Left sided hemiataxia, dys- and } \\
\text { hyperesthesia, hyperalgesia }\end{array}$ & 2 Years \\
\hline 5 & 70 & $\mathbf{F}$ & Old haemorrhage localised in left thalamus & $\begin{array}{l}\text { Severe sensory and mild motor } \\
\text { disturbances }\end{array}$ & $\begin{array}{l}\text { Right sided hemiataxia, dys- and } \\
\text { hyperesthesia, hyperalgesia }\end{array}$ & 4 Years \\
\hline 6 & 77 & $\mathbf{F}$ & $\begin{array}{l}\text { Small infarction in left thalamus (ventrolateral } \\
\text { nucleus), periventricular lucency }\end{array}$ & Sensorimotor disturbances & $\begin{array}{l}\text { Right side hemiataxia, hand tremor, } \\
\text { dys- and hypesthesia, hypalgesia }\end{array}$ & 7 Years \\
\hline 7 & 58 & $\mathbf{M}$ & $\begin{array}{l}\text { Infarction in right centrum semiovale and mild } \\
\text { cortical involvement }\end{array}$ & Sensorimotor disturbances & $\begin{array}{l}\text { Left sided minimal hemisensory } \\
\text { disturbance }\end{array}$ & 8 Years \\
\hline 8 & 37 & $\mathbf{M}$ & $\begin{array}{l}\text { Right temporoparietooccipital infarction due to } \\
\text { Moyamoya disease }\end{array}$ & $\begin{array}{l}\text { Subjective hemisensory } \\
\text { disturbances }\end{array}$ & $\begin{array}{l}\text { Left-sided hemispatial neglect, } \\
\text { disturbed combined sensations }\end{array}$ & 1 Month \\
\hline 9 & 49 & $\mathbf{M}$ & $\begin{array}{l}\text { Infarction in right temporoparietal cortex and } \\
\text { subcortex due to obstruction of middle } \\
\text { cerebral artery }\end{array}$ & Sensorimotor disturbances & $\begin{array}{l}\text { Left sided disturbed combined } \\
\text { sensations }\end{array}$ & 1 Month \\
\hline $\begin{array}{l}10 \\
11\end{array}$ & $\begin{array}{l}82 \\
72\end{array}$ & $\begin{array}{l}\mathrm{F} \\
\mathbf{M}\end{array}$ & $\begin{array}{l}\text { Infarction in left posterior inferior frontal lobe } \\
\text { Infarction in subcortex of left temporoparietal }\end{array}$ & $\begin{array}{l}\text { Speech disturbance } \\
\text { Speech disturbance }\end{array}$ & $\begin{array}{l}\text { Motor aphasia } \\
\text { Conduction aphasia }\end{array}$ & $\begin{array}{l}1 \text { Month } \\
3 \text { Months }\end{array}$ \\
\hline 12 & 61 & $\mathbf{M}$ & $\begin{array}{l}\text { Junction } \\
\text { Small infarction in anterior medial portion of } \\
\text { left thalamus }\end{array}$ & Mental deterioration & Amnestic syndrome & 7 Months \\
\hline
\end{tabular}

volunteers were subjected to PET study as control subjects.

PET was performed with a PCT-H1 (Hitachi, Japan) with four rings with 128 bismuth germanate oxide detectors providing seven views per scan cycle. The best spatial resolution was $7.4 \mathrm{~mm}$ full width at half maximum (FWHM) at the centre of the scan field, and axial resolution at the centre was $16 \mathrm{~mm}$ (slice thickness). Before PET study, $x$ ray CT (CTHSF, Hitachi) images were obtained to identify anatomical structures in the PET views. PET and $x$ ray CT scanners were located side by side and joined by rails on which the bed moved with the patient's position fixed, thus providing identical tomographic planes. The patient's head was fixed to the headrest to obtain a tomographic plane parallel to the orbitomeatal line. The initial positioning and the absence of head tilt during the scan were ensured by crossed beams projected on ink marks drawn on the patient's face. A transmission scan with Germanium-68 and gallium-68 was performed for 10 minutes for attenuation collection. Calibration factors between the PET scanner and well counter were obtained in each study. The oxygen-15 steady state technique $^{11}$ was used to measure regional cerebral blood flow (rCBF) and regional cerebral oxygen metabolic rate (rCMRO2). Oxygen-15 gas (750-1,100 MBq per minute) then oxygen15 labelled carbon dioxide (350-550 MBq per minute) were inhaled continuously. Scan data were collected for 5 to 8 minutes. The blood was sampled three times during each scan process from a cannulated radial artery and subjected to determinations of oxygen-15 radioactivity in whole blood and plasma as well as blood cell count and blood gas analysis. No correction was performed for intravascular oxygen-15 labelled oxyhaemoglobin.

Image data was processed with a Hitachi image processing computer with system subroutines to reconstruct functional images constituting $128 \times 128$ pixels. The region of interest was determined on both cerebellar hemispheres identified with $x$ ray CT by track ball. The region was set as the $x$ ray CT image on which the full width of both cerebellar hemispheres appeared. The outlines were traced by track ball, carefully avoiding the lateral sinuses and the fourth ventricles. The same region of interest was superimposed on cerebellar rCBF and rCMRO2 tomographic planes identical to the $x$ ray CT plane. The degree of asymmetry in $\mathrm{rCBF}$ and $\mathrm{rCMRO} 2$ was expressed by the asymmetry index (AI) defined as follows;

$$
\mathrm{AI}(\%)=|\mathrm{lt}-\mathrm{rt}| \times 200 /(\mathrm{lt}+\mathrm{rt})
$$

It and $\mathrm{rt}$ are the left and right cerebellar $\mathrm{rCBF}$ or CMRO2, respectively.

We analysed cerebellar rCBF and $\mathrm{rCMRO} 2$ with two way analysis of variance (ANOVA) with two fixed factors (a group factor with ataxic and non-ataxic and a side factor with ipsilateral and contralateral to the cerebral

Table 2 rCBF, rCMRO2, and asymmetry indices (AI) in ataxic and non-ataxic patients and normal controls

\begin{tabular}{|c|c|c|c|c|c|c|c|}
\hline \multirow[b]{2}{*}{ Group } & \multirow{2}{*}{$\begin{array}{l}\text { No. of } \\
\text { Cases }\end{array}$} & \multicolumn{2}{|l|}{ Age } & \multirow{2}{*}{$\begin{array}{l}\text { Mean }(S D) r C B F \ddagger \\
(\mathrm{ml} / 100 \mathrm{ml} / \mathrm{min})\end{array}$} & \multirow{2}{*}{$\begin{array}{l}\operatorname{Mean}(S D) A I(C B F) \S \\
(\%)\end{array}$} & \multirow{2}{*}{$\begin{array}{l}\text { Mean }(S D) \text { rCMRO2 } \\
(\mathrm{ml} / 100 \mathrm{ml} / \mathrm{min})\end{array}$} & \multirow{2}{*}{$\begin{array}{l}\text { Mean } \\
(\%)\end{array}$} \\
\hline & & Mean & S.D. & & & & \\
\hline $\begin{array}{c}\text { Ataxic } \\
\mathbf{C}^{\star} \\
\mathbf{I}^{\star}\end{array}$ & $\begin{array}{l}6 \\
6\end{array}$ & $59 \cdot 2$ & 16.5 & $\begin{array}{l}38.57(8.43) \\
44 \cdot 17(10 \cdot 47)\end{array}$ & $14.01 \|(2.60)$ & $\begin{array}{l}2.56(0.32) \\
2.89(0.32)\end{array}$ & $12.009(2.05)$ \\
\hline $\begin{array}{l}\text { Non-ataxic } \\
C^{\star} \\
I^{\star}\end{array}$ & $\begin{array}{r}6 \\
6 \\
13\end{array}$ & $59 \cdot 8$ & 16.0 & $\begin{array}{l}32.97(4.75) \\
35.02(6.41) \\
38.93(6.33)\end{array}$ & $6.44(5.47)$ & $\begin{array}{l}2.90(0.62) \\
2.91(0.57) \\
3.10(0.60)\end{array}$ & $3.05(0.73)$ \\
\hline
\end{tabular}

${ }^{\star} \mathrm{C}$ and $\mathrm{I}$ refer to cerebellar hemisphere contralateral and ipsilateral to side of supratentorial lesion, respectively.

†Mean values of $\mathrm{rCBF}$ and rCMRO2 in control group obtained from 26 cerebellar hemisphers in 13 subjects.
$\ddagger$ Not significant (two-way ANOVA). $\$ p<0.01$ (one-way ANOVA). "p $\| 0.0001$ and $p<0.05$, compared with mean values of control and non-ataxic groups, $\ddagger N o t$ significant (two-way ANOVA). \$p < 0.01 (one-way ANOVA). "p $\| 0.0001$ and $p<0$.
respectively ( $t$-test). $\mid p<0.0001$, compared with mean values of other two groups ( $t$-test). 
Figure 1 Distribution of $C B F$ and $C M R O 2$ values in patients with hemiataxia $(A)$ and without ataxia $(B)$. $O$ and $O$ indicate values for cerebellar hemispheres respectively contra- and ipsilateral cerebellar hemispheres to side of lesion. Hemispheres of each patient are connected by line.

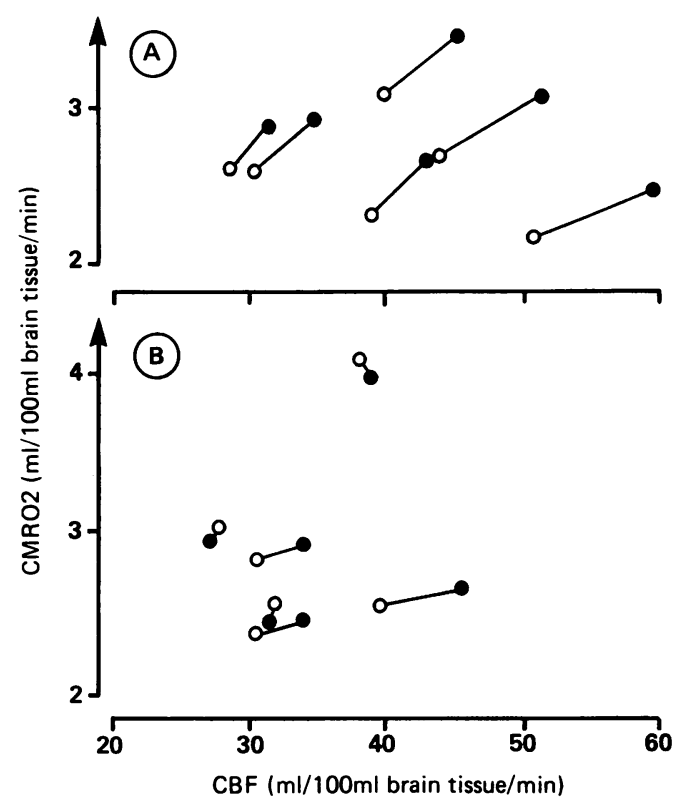

damage). We used one-way ANOVA to compare AIs for cerebellar rCBF and $\mathrm{rCMRO} 2$ in the ataxic, non-ataxic, and control groups. If the ANOVA showed significant variation, student's $t$ test was used to compare the group means.

\section{Results}

The rCBF and rCMRO2 values from the patients and control subjects are summarised in table 2. The patients were divided into two groups for data analysis as mentioned above, ataxic (cases 1 to 6 , figure 1A) and non-ataxic (cases 7 to 12, figure 1B). There was no significant difference in time from clinical onset to PET study between the two groups. Crossed cerebellar diaschisis (CCD) was judged present in cases showing an AI higher than the control mean plus $2 \mathrm{SD}$. CCD was observed on functional images for $\mathrm{rCBF}$ and $\mathrm{rCMRO} 2$ in all patients with ataxia (Figures $2 \mathrm{~A}$ and $2 \mathrm{~B}$ ). Of the patients without ataxia, cases 9 and 12 exhibited CCD in rCBF images but not in rCMRO2 images (figure $2 \mathrm{C}$ ), while the other cases showed no $\mathrm{CCD}$ in either functional image.

Interhemispheric comparisons of mean values of patients with hemiataxia showed clear reductions of $\mathrm{rCBF}$ and $\mathrm{rCMRO} 2$ in the contralateral cerebellar hemisphere (table 2). In patients without ataxia there was little difference between ipsilateral and contralateral hemispheric rCBF or rCMRO2 values. No group showed significant variation by two-way ANOVA on cerebellar rCBF or rCMRO2. On the other hand one-way ANOVA on AIs showed significant group effects in both the rCBF and rCMRO2. Compared to the indices of the control and non-ataxic groups, the AIs for $\mathrm{rCBF}$ and $\mathrm{rCMRO} 2$ in patients with ataxia were significantly elevated, indicating a clear reduction in $\mathrm{rCBF}$ and $\mathrm{rCMRO} 2$ in the contralateral cerebellar hemisphere.

\section{Discussion}

Only a few of the many reports on CCD refer to accompanying ataxia. ${ }^{45}$ This may indicate that the clinical significance of CCD has not yet been recognised. The present PET study, however, revealed that $\mathrm{CCD}$ does appear in some cases in association with hemiataxia on the same side as the decreased cerebellar perfusion and oxygen metabolism. Thalamic lesions are well known causes of contralateral loss of limb coordination, ${ }^{7}$ as demonstrated in cases 2, 4, and 6 (figure 2B and 2C). Parietal lobe injury ${ }^{12}$ has also been reported to cause contralateral hemiataxia, as demonstrated in case 1 . Ataxia due to injury in these regions is not always accompanied by disturbed deep or combined sensation. ${ }^{12}{ }^{13}$ All cases in the present study showed hemiataxia essentially of the cerebellar type. To our knowledge, there have been no cases reported of hemiataxia after thalamic or parietal injury in which CCD was demonstrated by functional imaging of cerebrocerebellar perfusion and metabolism, other than our preliminary report ${ }^{9}$ (figure 2). Muscle weakness and spasticity in our patients were sufficiently moderate to permit unmasking of limb ataxia on neurological examination. This possibly explains the prevalence of hemiataxia with CCD in our series.

CCD is postulated to be a distant effect caused by disruption of the corticopontocerebellar pathway, ${ }^{2}$ a principal cerebellar afferent connection. ${ }^{8}$ Although this mechanism explains cases 1 and 3, localised thalamic lesions in the other ataxic cases are unlikely to cause CCD via this afferent connection. Of the thalamic nuclei, the ventrolateral has been shown to have important connections with the contralateral cerebellar hemisphere via the dentato(rubro)thalamic pathway, a principal cerebellar efferent connection. ${ }^{8}$ On $x$ ray $\mathrm{CT}$, lesions involving the ventrolateral portion or adjacent regions were seen in all cases with hemiataxia after thalamic injury. We suggest that CCD with ataxia of thalamic origin is caused by disruption of cerebellar efferent fibres. Chung ${ }^{14}$ described four cases of retrograde crossed cerebellar atrophy confirmed by pathology in which the ventrolateral thalamus destroyed by brain tumour resulted in retrograde transneuronal atrophy of the contralateral cerebellar hemisphere. Case 12, in whom infarction in the left anterior medial thalamus which spared the lateral portion of the thalamus was noted, exhibited neither ataxia nor CCD on $\mathrm{rCMRO} 2$ imaging. This case also indicates the importance of localisation of intrathalamic damage in the development of CCD with ataxia.

There were two cases without ataxia in which CCD was observed on $\mathrm{rCBF}$ but not $\mathrm{rCMRO} 2$ imaging (figure 2C), while all cases with ataxia exhibited CCD on both images. This implies that cerebellar perfusion and metabolism in these two cases were uncoupled and that reduction of cerebellar metabolism rather than blood flow was an important causative factor. The cause of the uncoupling is not understood, but cerebral blood flow change has been shown to exceed cerebral metabolism change even under physiological conditions. ${ }^{1516}$ Although the region of interest was defined carefully on the 
(A)
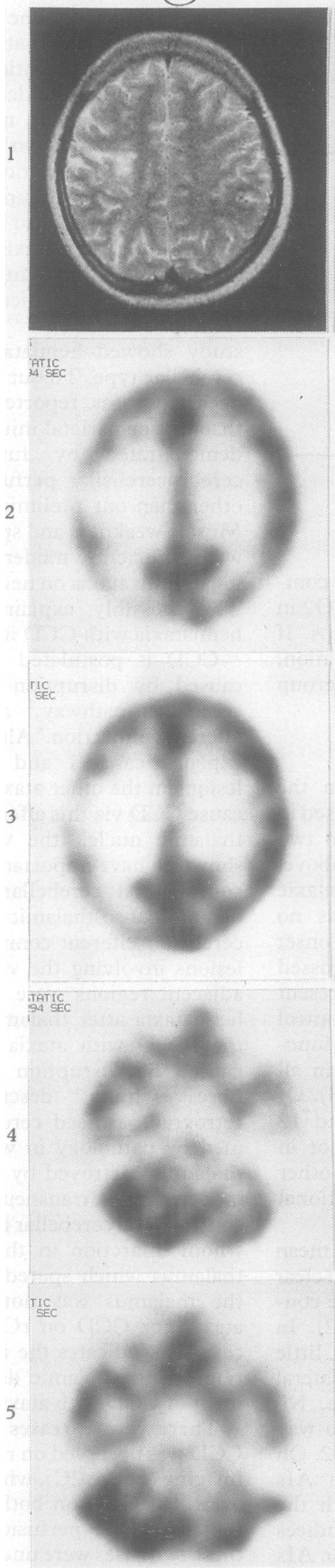

(B)
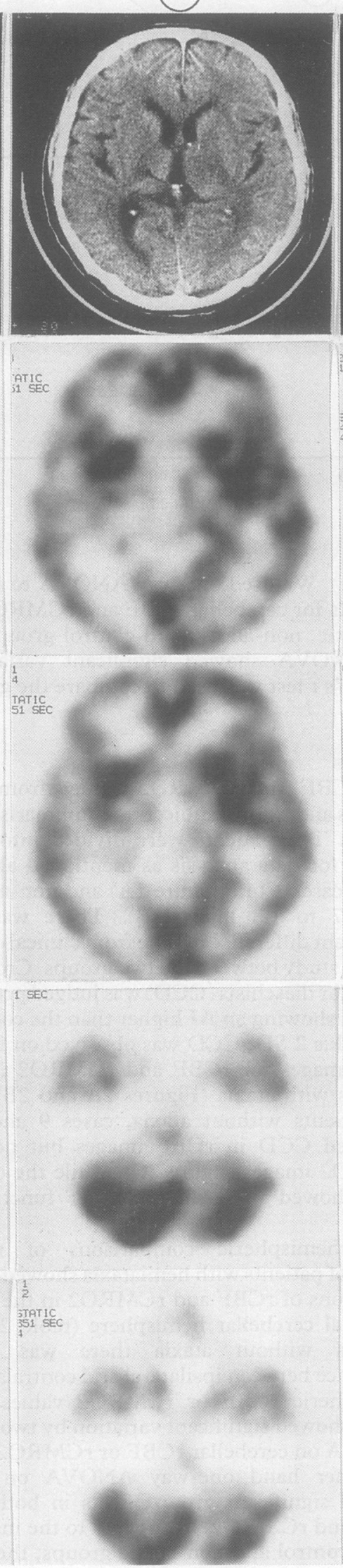

(C)
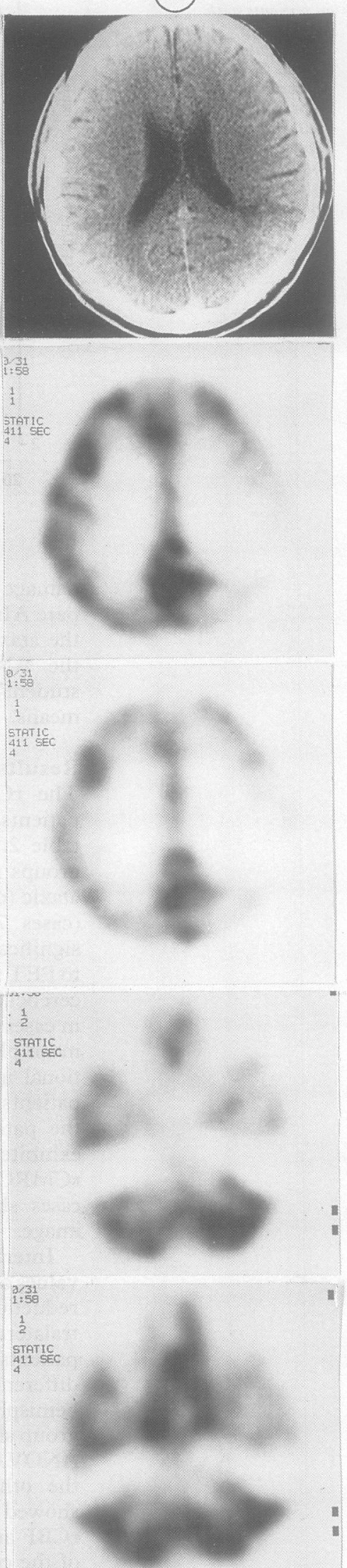

Figure $2 X$ ray CT (or MRI) and functional images of patients. 1: $x$ ray CT or MRI. 2 and 3: rCBF images at levels of lesion demonstrated by $x$ ray CT or MRI (2) and of cerebellar hemispheres (3). 4 and 5: rCMRO2 images at same levels as $r C B F$ images. The left side of the images corresponds with the left side of the brain. A: case 1 showed infarction of left parietal cortex and subcortical white matter on MRI. Crossed cerebellar diaschisis easily discernible in $C B F$ and CMRO2 images. B: case 2 exhibited small low density area involving ventrolateral nucleus of left thalamus.

Crossed cerebellar diaschisis was seen in both functional images. $C$ : case 9 showed border zone infarction in right temporoparietal areas. Left cerebellar perfusion was reduced as shown in $C B F$ image but oxygen consumption was preserved in both cerebellar hemispheres. 
cerebellar hemisphere delineated by $x$ ray CT, the possible presence of some artifacts should be taken into account. Radioactivity in the region was more or less influenced by that presenting in the lateral sinuses, as intravascular blood volume correction was not carried out in the present study.

Although CCD accompanied by ataxia was probably the result of damage to cerebellar afferent or efferent pathway, it is not necessarily linked to ataxia. ${ }^{17}$ Pappata et al ${ }^{17}$ reported that significant contralateral cerebellar hypometabolism was found in three of six patients with pure internal capsule infarction, suggesting a pathogenetic role for the corticopontocerebellar system. They also observed that contralateral hypometabolism occurred in two of six patients with thalamic lesions and made the assumption that this phenomenon also results either from damage to the ascending cerebellothalamocortical system or indirectly from hypometabolism of the cerebral cortex. Systemic association was not observed between crossed cerebellar hypometabolism and ipsilateral ataxia in their series. ${ }^{17}$ Their findings suggest that hypometabolism in the cerebral cortex, which is caused by transneuronal effect or by underlying cerebral ischaemia, also plays a pathophysiological role in CCD accompanied by ataxia. In our study, however, there seemed to be no assocition between ipsilateral hypometabolism in the cerebral cortex and CCD with ataxia (data not shown). A specifically designed study is required to reveal the pathogenesis producing CCD concurrent with ataxia.

We thank assistant Professor S Aoki (Department of Public
Health, Gunma University School of Medicine) for his helpful comment on statistical procedure.

1 Von Monakow C. Die Lokalisation im Grosshirn und der Abbau der Funktion durch Kortikale Herde. Wiesbaden: J F Bergmann, 1914:26-34.

2 Baron JC, Bousser MG, Comar D, Castaigne P. Crossed cerebellar diaschisis in human supratentorial brain infarction. Ann Neurol 1980;8:128.

3 Pantano P, Baron JC, Samson Y, Bousser MG, Derouesne C, Comar D. Crossed cerebellar diaschisis: further studies. Brain 1986;109:677-94.

4 Fukuyama H, Kameyama M, Harada $\mathrm{K}$, et al. Thalamic tumours invading the brain stem produce crossed cerebellar diaschisis demonstrated by PET. J Neurol Neurosurg Psychiatry 1986;49:524-8.

5 Bogousslavsky J, Regli F, Delaloye B, Delaloye-Bischoff A, Uske A, Despland PA. Hemiataxie et deficit sensitif ipsilateral: infarctus du territoire de l'artere choroidienne anterieure: diaschisis cerebelleux croise. Rev Neurol 1986; 142:671-6.

6 Sakai F, Aoki S, Kan S, Igarashi H, Kanada T, Tazaki Y. Ataxic hemiparesis with reductions of ipsilateral Ataxic hemiparesis with reductions of
cerebellar blood flow. Stroke 1986;17:1016-8.

7 Bogousslavsky J, Regli F, Uske A. Thalamic infarcts: clinical syndromes, etiology, and prognosis. Neurology 1988; syndromes,

8 Carpenter MB, Sutin J. Human neuroanatomy, 8th ed. Baltimore: Williams and Wilkins, 1983:454-92.

9 Tanaka M, Hirai S, Morimatsu M, Kanai H, Mizuno Y. Clinical and etiological study of crossed cerebellar diaschisis: report of two cases. Clin Neurol 1989;19:469-74.

10 Soisson T, Cabanis EA, Iban-Zizen MT, Bousser MG, Laplane D, Castaigne P. Hemiplegie motrice pure et tomodensitometrie. J Neuroradiol 1982;9:304-22.

11 Frackowiak RSJ, Pozzilli C, Legg NJ, et al. Regional cerebral oxygen supply and utilization in dementia, a
clinical and physiological study with oxygen-15 and positron tomography. Brain 1981;104:753-78.

12 Appenzeller O, Hanson JC. Parietal ataxia. Arch Neurol 1966;15:264-9.

13 Yagnik PM, Dhaduk V, Huen L. Parietal ataxic hemiparesis. Eur Neurol 1988;28:164-6.

14 Chung HD. Retrograde crossed cerebellar atrophy. Brain 1985;108:881-95.

15 Fox PT, Raichle ME. Focal physiological uncoupling of cerebral blood flow and oxidative metabolism during somatosensory stimulation in human subjects. Proc Natl Sci USA 1985;83:1140-4.

16 Lou HC, Edvinsson L, MacKenzie ET. The concept of coupling blood flow to brain function: revision required? Ann Neurol 1987;22:289-97.

17 Pappata S, Mazoyer B, Tran Dinh S, Cambon H, Levasseur M, Baron JC. Effects of capsular or thalamic stroke on metabolism in the cortex and cerebellum: a positron tomography study. Stroke 1990;21:519-24. 